\title{
Artificial intelligence in healthcare-opportunities and challenges
}

The term artificial intelligence (AI) evokes various responses amongst healthcare professionals, researchers and consumers (1). For some, AI could be panacea to all the problems ailing the healthcare sector and yet for others, a fad to be quickly dismissed. The truth is somewhere in between considering the efficacy of machine learning, a subset of AI, has been demonstrated in different areas of medicine with improved diagnosis and treatment being made possible (2). In other instances, AI has been found to useful in drug discovery, infectious disease surveillance and even in aiding efficient healthcare administration. Also, there has been increasing support from governments and the private sector in funding AI in healthcare research and development with a growing number of AI enabled medical software being approved for use in the market (3). However, AI as a new technology, especially so in the realm of medicine, has to be carefully evaluated for its safety and efficacy in achieving its intended outcomes (4). There is requirement for some preparatory work and laying out the ground for integration of AI in routine clinical workflows, while supporting more research and development of AI in healthcare applications.

In this special edition, researchers and clinicians from across the world outline the scale of the use of AI in various contexts and key issues to consider in implementing AI in healthcare strategies. Covered in this edition is the ability of AI to enable precision medicine, issues in hospitals using AI for strategic decision making, how AI has been used in the Indian healthcare sector, the role of AI in managing respiratory diseases, the ability of AI to improve the quality of healthcare, why AI and healthcare need each other, and the key data governance challenges involved in implementing AI in healthcare. The collected articles promise not only a good review of AI in healthcare but also a balanced perspective for readers as to what AI can do for healthcare.

\section{Acknowledgments}

The editors thank the various authors who have contributed to this special edition.

Funding: None.

\section{Footnote}

Provenance and Peer Review: This article was commissioned by the editorial office, Fournal of Hospital Management and Health Policy for the series "AI in Healthcare - Opportunities and Challenges". The article did not undergo external peer review.

Conflicts of Interest: All authors have completed the ICMJE uniform disclosure form (available at http://dx.doi.org/10.21037/ jhmhp-21-31). The series "AI in Healthcare - Opportunities and Challenges" was commissioned by the editorial office without any funding or sponsorship. Sandeep Reddy, Jenifer Sunrise Winter and Sandosh Padmanabhan served as the unpaid Guest Editors of the series. Sandeep Reddy serves as an unpaid editorial board member of fournal of Hospital Management and Health Policy from June 2019 to May 2021. The authors have no other conflicts of interest to declare.

Ethical Statement: The authors are accountable for all aspects of the work in ensuring that questions related to the accuracy or integrity of any part of the work are appropriately investigated and resolved.

Open Access Statement: This is an Open Access article distributed in accordance with the Creative Commons AttributionNonCommercial-NoDerivs 4.0 International License (CC BY-NC-ND 4.0), which permits the non-commercial replication and distribution of the article with the strict proviso that no changes or edits are made and the original work is properly cited (including links to both the formal publication through the relevant DOI and the license). See: https://creativecommons.org/licenses/by-nc$\mathrm{nd} / 4.0 /$. 


\section{References}

1. Wang F, Casalino LP, Khullar D. Deep Learning in Medicine-Promise, Progress, and Challenges. JAMA Intern Med 2019;179:293-4.

2. Reddy S, Fox J, Purohit MP. Artificial intelligence-enabled healthcare delivery. J R Soc Med 2019;112:22-8.

3. Jiang F, Jiang Y, Zhi H, et al. Artificial intelligence in healthcare: past, present and future. Stroke Vasc Neurol 2017;2:230-43.

4. Reddy S, Allan S, Coghlan S, et al. A governance model for the application of AI in health care. J Am Med Inform Assoc 2020;27:491-7.

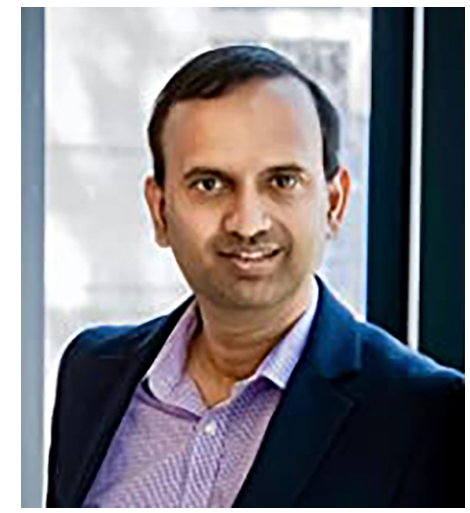

Sandeep Reddy

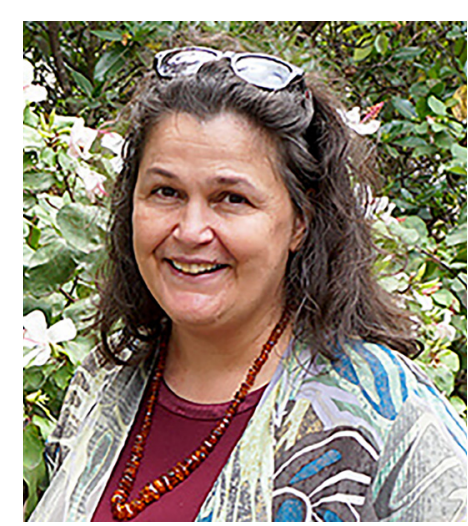

Jenifer Sunrise Winter

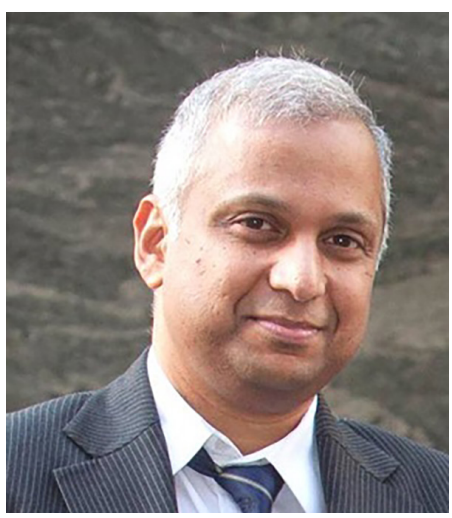

Sandosh Padmanabhan

Sandeep Reddy

Deakin School of Medicine, Geelong, VIC, Australia

(Email: sandeep.reddy@deakin.edu.au)

Jenifer Sunrise Winter

School of Communications, University of Hawaii at Manoa, Honolulu, HI, USA;

(Email: jwinter@hawaii.edu)

Sandosh Padmanabhan

Cardiovascular Genomics and Therapeutics, Institute of Cardiovascular and Medical Science,

University of Glasgow, Glasgow, UK.

(Email: sandosh.padmanabhan@glasgow.ac.uk)

Received: 21 April 2021; Accepted: 07 May 2021; Published: 25 September 2021.

doi: $10.21037 /$ jhmhp-21-31

View this article at: http://dx.doi.org/10.21037/jhmhp-21-31

doi: $10.21037 /$ jhmhp-21-31

Cite this article as: Reddy S, Winter JS, Padmanabhan S. Artificial intelligence in healthcare-opportunities and challenges. J Hosp Manag Health Policy 2021;5:23. 